\title{
Location of Hospital Waste Disposal Site With FSWARA-GIS-MAIRCA Hybrid Algorithm
}

\section{CURRENT STATUS: POSTED}

Research Square

Fatemeh Ramila Heydari Pirbasti

Islamic Azad University South Tehran Branch

f.heydaripirbasti@gmail.comCorresponding Author

ORCiD: https://orcid.org/0000-0002-8336-3514

Mahmoud Modiri

Islamic Azad University South Tehran Branch

Kiamars Fathi Hafashjani

Islamic Azad University South Tehran Branch

Alireza Rashidi Komijan

Islamic Azad University Firoozkooh Branch

DOI:

10.21203/rs.2.22537/v1

SUBJECT AREAS

Environmental Policy

KEYWORDS

Disposal Site, Waste, Hospital, Location, FSWARA, GIS, MAIRCA 
Abstract

Background: One of the major environmental issues facing most societies is the management of waste, industrial, medical and hazardous waste. Locating is an activity that analyzes the capabilities of an area in terms of whether the land is suitable for a particular application. The metrics used in location vary by application type, but they are all aligned to select the right location. Choosing the right burial site for waste is the most important step in waste management. Inappropriate burial selection causes contamination of water, soil and air in the area. The ultimate goal is to find the most suitable location that has the least impact on the environment and natural resources around, and is economically the least costly and engineered.

Results: In this study, we chose south of Tehran as a case study to implement the FSWARAGISMAIRCA Hybrid Algorithm. Selecting inappropriate locations for hospital waste disposal site at the southeast of Tehran province is one of the environmental problems of this region causing damage to the environment and pollution of ground waters. Since waste disposal site is the most economic, accepted, and important method in most areas, the present study aimed to locate the hospital waste disposal site at the southeast of Tehran province. Using fuzzy Delphi method, nine criteria (slope, height, soil type, distance from fault, distance from surface water, depth of ground waters, distance from residential areas, distance from hospitals and distance from road) were finally selected as the final criteria. Then, the desired criteria were weighed using the FSWARA and entered the GIS system as information layers to calculate the final maps for the appropriate zones, which eight locations were selected for waste disposal site.

Conclusions: Finally, using the MAIRCA method, the selected locations were ranked and finally among these eight locations, the fourth point was selected as the final location for hospital waste disposal site at the southeast of Tehran. According to the desired criteria with 34 degree slope, 1008 meters high, 3.4841 meters distance from fault, 8.4428 meters distance from surface water, 12 meters depth of ground waters, 457 meters distance from residential areas, 6.4749 meters distance from hospitals, and 1598 meters distance from road.

Full-text 
Due to technical limitations, full-text HTML conversion of this manuscript could not be completed.

However, the manuscript can be downloaded and accessed as a PDF. 